\title{
Resin Dermatitis in a Car Factory
}

\author{
H. O. ENGEL and C. D. CALNAN \\ From the Ford Motor Company Ltd., Dagenham, Essex \\ and The Institute of Dermatology, St. Fohn's Hospital for Diseases of the Skin, London, W.C.2.
}

An outbreak of dermatitis in a car assembly factory is described; it affected 50 workers who handled rubber weatherstrips coated with an adhesive. The adhesive was found to contain para-tertiary butyl phenol (P.T.B.P.) formaldehyde resin. Of those patch tested $70 \%$ gave positive reactions to the adhesive and $65 \%$ to the resin. Improved methods of handling and personal protection succeeded in arresting the occurrence of dermatitis. Barrier creams gave no protection in these circumstances. The episode illustrates the different preventive control methods which have to be tried when dealing with a simple skin hazard which cannot be abolished.

In the latter part of 1962 a number of new cases of dermatitis of the hands and forearms were reported to the medical department of a car assembly factory, where all patients with skin trouble are seen by one doctor at a daily clinic (Fig. I). Altogether 50 cases of dermatitis occurred during the three years from June 1962 to May 1965 among operators who stick weatherstrips (or 'door rubbers') on the car doors or boot lids. They came from three different assembly lines in roughly equal numbers. There were about 150 operators on this particular operation during these three years. The exact number at risk is not known because of considerable mobility of labour on the assembly lines.

\section{Process}

Weatherstrips, which are usually manufactured

Received for publication September 8, 1965. from rubber or rubber-like polymers, function as seals on car doors and engine compartment and boot lids to prevent dust, water, etc. from entering into the interior.

The surface of the weatherstrip is coated with a liquid adhesive. This operation is carried out on a roller coating machine, and the operators who pull the rubbers through were not affected. A priming adhesive is then applied by brush to the edges and channels of the car by another set of operators.

After a predetermined time interval, a further set of operators activate the adhesive, i.e., make it tacky, by running a rag soaked in toluol around the coated surfaces of the weatherstrips. As soon as this operation is completed the weatherstrip is fitted to the car (Fig. 2). This involves a fair amount of manipulation with the fingertips, particularly on the newer models, in order to get a proper fit into the channels. The rag used for the re-activation is repeatedly dipped into a small tin of toluol and then

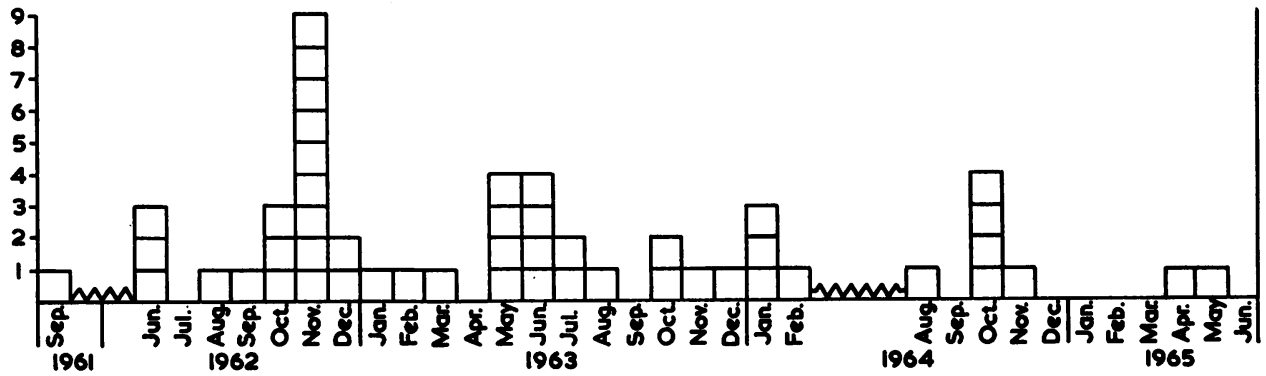

FIG. I. Incidence of dermatitis. 


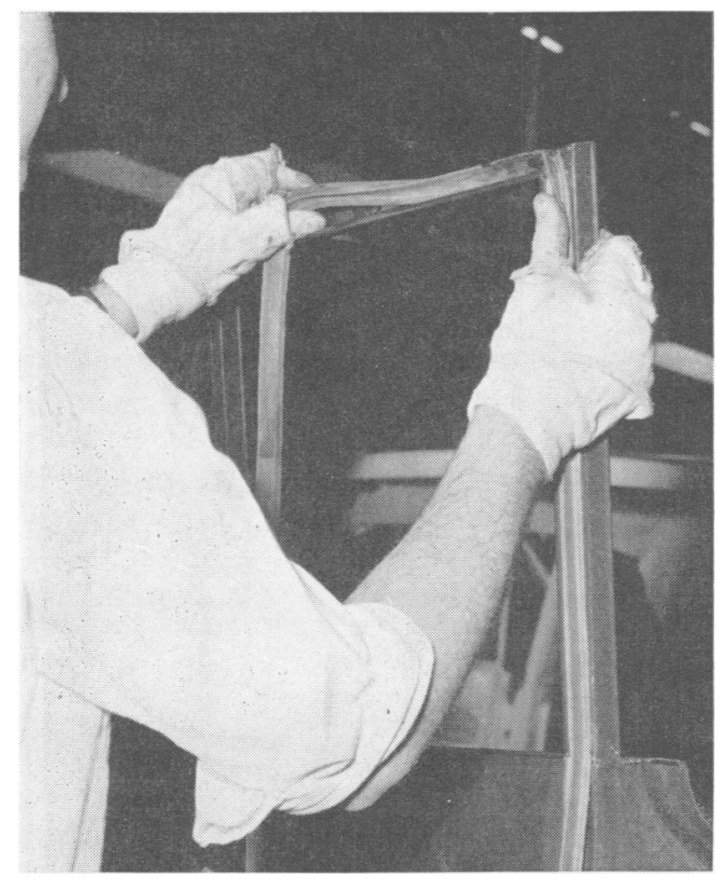

FIG. 2. Fitting the weatherstrip to a car door.

wrung out. During use it picks up adhesive and soon becomes impregnated with a mixture of toluol and adhesive.

The new and improved adhesive had been introduced at the end of June 1962.

\section{Investigation}

Three materials were handled by all these employees: (I) the rubber weatherstrips, supplied by three different firms for some years; (2) adhesives $\mathrm{A}$ and $\mathrm{B}$, both from the same manufacturer; and (3) toluol, which is the solvent used to 'activate' the adhesive.

The rubber weatherstrips were not thought to be the likely cause. Some of these strips were made of natural and some of synthetic rubber. They came from various suppliers and had not changed in composition for a long time. The toluol would be expected to cause only rare cases of primary irritant dermatitis rather than a number of cases of sensitization within a short period. The adhesives were therefore suspected as a likely cause.

The first five patients were referred to St. John's Hospital for patch testing with a standard set of test substances (Calnan, 1955) as well as the two adhesives, the rubbers, toluol, and a specimen phenolic resin. Of the five patients, four reacted to both adhesives and nothing else. The manufacturers then supplied us with the four solid ingredients of their products for patch testing, two being phenolformaldehyde resins, one a cumarone resin, and one zinc-calcium resinate.

Of 50 patients patch tested, $35(70 \%)$ reacted to the adhesives. The patients were further patch tested with the resins, and $32(65 \%)$ reacted to one and 29 to the other phenolic resin, none to the other resins. From these tests it was evident that both adhesives $\mathbf{A}$ and $\mathbf{B}$ contained sensitizing phenolformaldehyde resins.

Two years previously there had been a small outbreak of similar dermatitis in men engaged in sticking door pads, which was traced to the use of P.T.B.P. formaldehyde resin with toluol, which was confirmed by patch testing. This had subsided when the sticking of door pads was discontinued due to an engineering change. This resin is a wellknown cause of contact dermatitis, especially in the shoe industry (Malten, 1958; Calnan and Harman, 1959; Malten and van Aerssen, 1962).

The manufacturers were therefore requested to give further details of the resins, and it transpired that both consisted essentially of P.T.B.P. formaldehyde resin as suspected, and no doubt this is the cause of these cases of dermatitis. New cases which have arisen since May 1963 have been patch tested with P.T.B.P. 10\% in soft paraffin, but only four out of 29 cases tested gave a weak reaction to the phenol alone (in contrast to $65 \%$ positive reactions to the resin).

\section{Clinical Features}

Population at Risk The door rubber operation was carried out by a number of workmen, all male, almost all white, either continuously for months or sporadically in rotation for a shift or two, and it is thought that some 150 employees have been at risk during the three-year period of this outbreak. Two equal-sized shifts are worked, and the difference in incidence per shift was not significant.

Age and Exposure of Patients The age distribution of the patients was 21 to 58 with an average of 37 years. This is exactly the average age of the assembly workers generally. Men of all ages between 21 and 58 were proportionately affected, and older workers were not more susceptible than young men. The patients had been working in this factory for between seven weeks and 28 years, with an average of eight years' service. They had been exposed to the adhesives for one day to two years before the onset of the eruption. The average period of contact before onset was 17 weeks, but in five 
cases the rash started within 24 hours of handling the adhesive.

Morphology The eruption was generally an erythematous vesicular rash of the fingers and hands (Table I). In four cases the eruption was limited to the forearms, and these patients showed a papular or follicular eczema without vesicles or erythema.

TABLE I

Main Character of ERuption

\begin{tabular}{lc} 
Type & No. of Cases \\
\hline Vesicular, often with erythema & 37 \\
Erythema, peeling, sometimes fissuring & 9 \\
Papular & 2 \\
Follicular & 2
\end{tabular}

Distribution of Dermatitis The fingers were affected in 33 cases, the rest of the hands in 27 cases, and the wrists and forearms in 14 cases. None of the patients had any rash on the face, neck, or any parts other than the upper extremities.

In many cases only the fingers were affected at first and some had the rash on one hand only.

Severity The average duration of the eruption was 12 weeks. In four patients it cleared up within a week, but in three it had persisted for up to two and a half years at follow-up in July 1965. Two patients left the company still suffering from dermatitis. All other patients were clear. Three of the patients have had to be away from work, two for one week and one for six weeks.

Previous History A previous history of some form of exogenous dermatitis was obtained in nine cases, and two had had some previous pompholyx or palmar eczema. The rash had been present on an average for five and a half days before the medical officer was consulted; in some cases delay was due to the night shift.

Treatment The treatment was with potassium permanganate soaks, hydrocortisone, 'Vioform-
cortisone'(Ciba)or fluocinolone acetonide('Synalar', I.C.I.). No oral steroids were given to any patient. All but four mildly affected patients were transferred to other assembly jobs in the factory, most of them permanently.

Barrier Creams Two barrier creams have been in use on the assembly lines concerned, one a general purpose cream (A) and the other a cream specially recommended for synthetic adhesives (B). Another special cream was introduced later (C).

TABLE II

Barrier Creams Used Before ONSet

\begin{tabular}{lcc} 
Barrier Cream & No. of Patients & Total \\
\hline A & II \\
B & 2 I & \\
C & 2 & 36 \\
A and B & 2 & 3 \\
None & 14 & 50
\end{tabular}

Seventy-two per cent of patients had been using a barrier cream (Table II). These proportions are thought to be similar to those among all employees at risk, from enquiries among a sample of operators. It appears therefore that barrier creams gave no protection under these conditions. In fact since toluol is a powerful solvent it is unlikely that the creams would resist its action for long. A silicone barrier cream might be better suited, but this could not be used because parts of the paint work may be subsequently resprayed for paint repairs, and silicone from the hands of operators would seriously interfere with the results. Barrier cream is probably useful in preventing irritant dermatitis but would not be expected to protect against allergic sensitization, which only requires minute amounts of the allergen to reach the predisposed skin.

Patch Tests The adhesives and resins were made up in a $10 \%$ dilution in yellow soft paraffin. The tests were carried out with closed patches (Dalmas $984 \mathrm{~W}$ ) and read after 48 and 96 hours.

TABLE III

Patch Test Results nn 50 Patients

\begin{tabular}{|c|c|c|c|c|c|c|}
\hline \multirow[t]{2}{*}{ Result } & \multicolumn{2}{|c|}{ Adhesive } & \multicolumn{2}{|c|}{ Phenolic Resin } & \multirow{2}{*}{$\begin{array}{l}\text { Cumarone } \\
\text { Resin }\end{array}$} & \multirow[t]{2}{*}{ Resinate } \\
\hline & $A$ & $B$ & $I$ & $I I$ & & \\
\hline $\begin{array}{l}+,++,+++ \\
\pm \\
\overline{\text { Not tested }}\end{array}$ & $\begin{array}{r}35 \\
1 \\
14 \\
0\end{array}$ & $\begin{array}{r}34 \\
4 \\
12 \\
0\end{array}$ & $\begin{array}{r}32 \\
5 \\
12 \\
1\end{array}$ & $\begin{array}{r}29 \\
3 \\
17 \\
1\end{array}$ & $\begin{array}{r}0 \\
0 \\
38 \\
12\end{array}$ & $\begin{array}{r}0 \\
0 \\
40 \\
10\end{array}$ \\
\hline
\end{tabular}


Reactions were graded,+++ , or +++ . A few patients gave a slight reaction to one or other patch, and these were recorded separately as \pm (Table III).

Follow-up Most cases cleared up rapidly after removal from contact. Four patients with mild reactions did not change their job but avoided contact by using only a brush and by exercising the maximum degree of care, without recurrence. The average duration of 3.0 months contrasts with 5.3 months in our series of chromate dermatitis (Engel and Calnan, 1963). The present course may have been shortened by the use of fluocinolone, which was not used in the previous series.

Recurrence A relapse on return to the adhesive job occurred in three cases but settled quickly when the operator was removed from the work once more. Four men had a relapse while away from the job but cleared up with further topical treatment.

\section{Control Measures}

We considered the following preventive measures to try to protect the operators, and only a combination of these is showing results.

Abolition Abolition of the hazard by omitting the offending resin would, of course, be the ideal solution. The present shape of the doors and frames, however, makes the use of adhesives essential, but it is now proposed to use a mechanical 'fix' on future models. This requires an engineering change in the shape of the door channels and may slightly increase the cost, but in return it will completely eliminate the hazard. Meanwhile other measures are being employed.

Substitution In spite of efforts by at least four adhesive manufacturers no substitute with adequate properties has so far been found. We have been offered several alternative formulations, but every time investigation shows that P.T.B.P. resin is an essential ingredient.

Enclosure Enclosure or separation of the process was not possible, since the operation has to be carried out on a continuous assembly line and handling cannot be avoided.

Mechanization This is sometimes effective in reducing handling, e.g., an automatic mixing and dispensing machine for epoxy resin and hardener eliminated unnecessary contact. In this instance each rubber has to be applied accurately to the door edge and moulded to the channel, and some handling is unavoidable.
Working Methods The toluol and adhesivesoaked cloths used to activate the material have been forbidden, and operators are now given flow brushes with which to apply the solvent; this has greatly reduced exposure. A rubber flange has also been fitted to the brush handles which prevents the solvent from running on to the hands and allows it to evaporate.

Selection of Employees It is not possible to select those liable to sensitization. Prophetic patch tests were not considered justifiable or helpful. Any operator, however, who developed a rash was removed from the job, so that there has been a certain amount of selection of those resistant to sensitization to this adhesive.

Limitation of Exposure This was not possible on the assembly lines, where each man must do his allotted operation and requires training to get proficient; frequent changes mean a loss of efficiency.

Washing Facilities These are some distance from the lines but improvement proved impracticable. Soap and water would not of themselves have been adequate cleansers.

Skin Cleansers Most operators used an allpurpose skin cleanser. In May I963 a special resin skin cleanser was introduced, obtainable from dispensers directly at the workplace and wiped off with cotton waste. This reduced contact with the resin and also avoided the use of toluol as a cleanser.

Barrier Creams The normal barrier cream A was replaced by a special resin-resistant barrier cream B, and later another product was tried (C). Their effect is probably mainly to make subsequent removal of the resin easier; they do not appear to have any effect on the incidence of dermatitis.

Gloves We tried various plastic, P.V.C. and nitrile gloves, but they all failed, either because they proved to be too thick and clumsy for dexterity or because they became tacky with toluol contact. Cotton gloves were not found useful because employees would cut off two or three fingertips to improve dexterity, thus defeating the object.

Supervision, Training, and Housekeeping A special effort was made with the help of the supervisors and safety officers to make operators conscious of hygiene measures and good housekeeping and to avoid excessive use of adhesive and solvent and unnecessary spillage. Efficient skin cleansing, adequate laundering, and facilities to attend the medical department were all encouraged. 


\section{Discussion}

P.T.B.P. resin is a very useful adhesive because of its rapid sticking action and resistance to heat and because it continues to harden with the passage of time. It is probably used in other adhesives where its dermatitic properties have not yet been described.

Considerable pressure was needed to persuade both foremen and operators to discard the toluolsoaked cloths, but, as is seen from Fig. I, the outbreak gradually ceased and there have been only sporadic cases since February 1964. Although there has been no change in the adhesives, the improved methods of application by the use of flow brushes and the improved personal protective measures appear to have been effective in preventing further cases of dermatitis.

The use of toluol may have been an additional factor in this outbreak. Its degreasing action and damage to the keratin protection of the skin presumably predispose to sensitization to P.T.B.P. Here again the multiplicity of the factors leading to the development of dermatitis is evident. P.T.B.P. used without solvent or solvent without P.T.B.P. did not cause any dermatitis. It appears that the combination of primary irritant and minor trauma from pulling adhesives off the skin, sensitization, and possibly improper hand cleansing methods all combine to cause skin damage, where each factor individually may be without adverse effect.

It is an unfortunate problem that the new very efficient synthetic resins, such as epoxy (Grandjean, 1957), polyester (Bourne and Milner, 1963), and tertiary butyl phenol formaldehyde resins, also present increased skin hazards to those who handle them. Adhesive manufacturers should be made aware of the risks attending their uses, so that users may be warned and research to discover adhesives with less dermatitic properties may be continued.

We should like to thank Dr. M. Newhouse for helpful advice, and th.e management of Ford Motor Company and Dr. J. N. Macdonald for permission to publish this article.

\section{REFERENCES}

Bourne, L. B., and Milner, F. J. M. (1963). Brit. F. industr. Med., 20, roo.

Calnan, C. D. (1955). Trans. St. Fohn's Hosp. derm. Soc. (Lond.), No. 34, p. 37.

, and Harman, R. R. M. (1959). Ibid., No. 43, p. 27.

Engel, H. O., and Calnan, C. D. (1963). Brit. F. industr. Med., 20, I92.

Grandjean, E. (1957). Ibid., 14, I.

Malten, K. E. (1958). Dermatologica (Basel), 117, 103.

-, and van Aerssen, R. G. L. (1962). Berufsdermatosen, I0, 264. 